\section{Reply to Rachlin's comment}

\section{GENE M. HEYMAN and R. DUNCAN LUCE Harvard University \\ Cambridge, Massachusetts 02138}

The primary purpose of our article was to demonstrate unambiguously that matching does not necessarily follow from maximization of overall reinforcement rate, as appears to have been suggested by some writers. Evidently, Rachlin (1979) now accepts that as some slight contribution, since he raises the question, "But are there switching patterns for which matching and maximizing are the same?" which strongly implies that he no longer believes it to be true of all switching patterns. It is a good question, one to which we do not know the answer. We suspect it may be a very difficult one to answer rigorously, and we are not especially embarrassed at not having included its solution.

However, there is another sense in which Rachlin clearly does not take our result seriously. He goes on to say, "What is the relation of these patterns [i.e., those for which maximizing implies matching] to those actually observed (rather than assumed) in Figures 1 and 2? Until such questions are answered, one cannot take seriously the authors' version of maximizing." We suspect he is objecting not so much to our concept of maximizing, which seems quite ordinary, as to our assumed exponential model of the switching process. In effect, he is saying that this is so far from the behavioral truth that the example lacks empirical significance even if it does have some logical import. And implicitly, he is suggesting, without providing any real support, that there is a broad class of switching patterns for which maximizing yields matching or something close to it, and the observed behavioral patterns fall in this class. We cannot deal with the latter conjecture, but it may be useful to look carefully at Rachlin's various factual claims both about the data on switching and the observed deviations from matching.

(1) Rachlin suggests that the data shown in Figures 1 and 2 do not conform to the exponential assumption. However, in the study from which these data were obtained (Heyman, 1979), changeover probabilities were stationary for all run lengths in 16 of 24 tests (chi-square) and stationary for runs of two or more in an additional four tests. Moreover, contrary to Rachlin's speculations, the distribution of short run lengths has little effect on the relationship between the distribution of time between the schedules and the overall reinforcement rate (the variables of interest according to the maximizing theory). For example, our Table 1 shows that the exponential model predicted the relationship between time proportions and overall reinforcement rate with no more than $1 \%$ error for sessions in which random switching did not occur (see Heyman, 1979).

(2) Our Figure 3 shows that maximizing and matching programmed reinforcement proportions in the independent procedure are not the same. Rachlin argues that this is not critical to the reinforcement rate maximizing theory because programmed and obtained reinforcement proportions differ. However, it turns out that programmed and obtained values frequently approximate the same value. For three studies reviewed by de Villiers (1977), the average differences were $.7 \%$ (Baum \& Rachlin, 1969), 1.0\% (McSweeney, 1975), and .3\% (Silberberg \& Fantino, 1970).

(3) Our Figure 4 shows that there is about a $10 \%$ to $13 \%$ difference between matching to obtained reinforcement proportions and the maximizing value in interdependent conc VI VI schedules. Rachlin's response is that the "universality of matching is less certain on interdependent schedules." Other researchers, though, conclude, "The available evidence suggest that the two methods [interdependent and independent] are equivalent with regard to the relationship between relative frequency of responding and ... the relative frequency of reinforcement" (Menlove, Moffit, \& Shimp, 1973). Stubbs and Pliskoff (1969) concur, and de Villiers' review shows that the regression lines fitting behavior proportions to reinforcement proportions for interdependent procedures fall within the range set by the independent conc VI VI arrangement.

(4) Rachlin claims that the literature shows that deviations from matching are generally in the direction predicted by the maximizing values of the Poisson models. The basis for this assertion is not evident. For an independent conc VI VI procedure, the exponential model predicts that overmatching programmed reinforcement proportions maximizes reinforcement rate. But for three studies in which it was possible to make the necessary comparisons (presently there is no relevant literature review), both overmatching and undermatching occurred, with a slightly greater tendency for undermatching (Baum \& Rachlin, 1969; Silberberg \& Fantino, 1970; Trevett Davison, \& Williams, 1972). For an interdependent schedule, the exponential maximizing values require at least a $10 \%$ deviation toward undermatching. Yet Stubbs and Pliskoff (1969) found that time proportions overmatched obtained and programmed reinforcement proportions (for each subject, the slope of the regression line was greater than 1.0). Many factors are likely to cause deviations from perfect matching, but these data suggest that maximizing is not one of them. 
Rachlin's comments do, however, emphasize a point to which we have not given attention. He suggests that the differences between the matching and maximizing values displayed in Figure 3 (above) would shrink had matching to obtained reinforcement proportions been compared. This is correct. Our Equation 11 predicts that maximizing and matching to obtained reinforcement proportions do not differ by more than a few percentage points in an independent conc VI VI schedule which does not employ a changeover delay (for the method of predicting the obtained reinforcement proportions, see Herrnstein \& Heyman, 1979). However, even if equality had been obtained, it would still be the case that maximizing reinforcement rate is not a necessary condition for matching, since subjects match in interdependent conc VI VI schedules and conc VI VR schedules (Herrnstein \& Heyman, 1979).

A critical assumption for the theory that matching is the result of reinforcement rate maximization is that instrumental behavior is constrained by only one variable-the nominal reinforcement rate. Mathematical analysis, experimental results, and logic show that this assumption is incorrect.

\section{REFERENCES}

Baum, W. M., \& RAchlin, H. C. Choice as time allocation. Journal of the Experimental Analysis of Behavior, 1969, 12, 861-874.
DE Villiers, P. A. Choice in concurrent schedules and quantitative formulations of the law of effect. In W. K. Honig \& J. E. R. Staddon (Eds.), Handbook of operant behavior. Englewood Cliffs, N.J: Prentice-Hall, 1977.

Herrnstein, R. J., \& Heyman, G. M. Is matching compatible with reinforcement rate maximization on concurrent VI VR? Journal of the Experimental Analysis of Behavior, 1979, in press.

Heyman, G. M. A Markov model description of changeover probabilities on concurrent variable-interval schedules. Journal of the Experimental Analysis of Behavior, 1979, in press.

Menlove, R. L., Moffitt, M., \& Shimp, C. P. Choice between concurrent schedules. Journal of the Experimental Analysis of Behavior, 1973, 19, 331-344.

McSweEney, F. K. Matching and contrast on several concurrent treadle-press schedules. Journal of the Experimental Analysis of Behavior, 1975, 23, 193-198.

Rachlin, H. Comment on Heyman and Luce: "Operant matching is not a logical consequence of maximizing reinforcement rate." Animal Learning \& Behavior, 1979, 7, 267-268.

Silberberg, A., \& Fantino, E. Choice, rate of reinforcement, and the changeover delay. Journal of the Experimental Analysis of Behavior, 1970, 13, 187-197.

StubBs, D. A., \& Pliskoff, S. S. Concurrent responding with fixed relative rate of reinforcement. Journal of the Experimental Analysis of Behavior, 1969, 12, 887-895.

Trevett, A. J., Davison, M. C., \& Williams, R. J. Performance in concurrent interval schedules. Journal of the Experimental Analysis of Behavior, 1972, 17, 369-374.

(Received for publication December 13, 1978; accepted December 13, 1978.) 